The Use of Facebook in the Maternal Grief Process: An Exploratory Qualitative Study

\author{
Diana Perluxo ${ }^{\mathrm{a}}$
}

Rita Francisco ${ }^{\mathrm{a}, 1}$

${ }^{a}$ Universidade de Lisboa, Faculdade de Psicologia, Portugal

Alameda da Universidade, 1649-013 Lisboa

${ }^{1}$ Present address: Universidade Católica Portuguesa, Faculdade de Ciências Humanas, Portugal

Palma de Cima, 1649-023 Lisboa, Portugal

Corresponding author:

Rita Francisco, ritafrancisco@fch.lisboa.ucp.pt

Phone number: +351217214018

Palma de Cima, 1649-023 Lisboa, Portugal

\title{
Acknowledgements
}

This study was partially supported by the Research Center for Psychological Science (UID/PSI/04527/2013) of the Ministry of Science and Technology (FCT, Portugal). We would like to express our appreciation to all the participants. 


\begin{abstract}
This study seeks to explore the potential implications of Facebook use in the process of maternal grief. The participants were 11 women who had lost their children due to accidents or prolonged illness. Semi-structured interviews were conducted and subjected to Thematic Analysis. The participants stated that they used Facebook to receive support, to identify with other mothers, to remember the child who died, to access the child's information, to honor him/her, and to express their feelings. The use of Facebook can play a very important role in the initial phase of grieving due to the functions of this social network.
\end{abstract}

Keywords: death, maternal grief, Facebook, virtual grief. 
The Use of Facebook in The Maternal Grief Process: An Exploratory Qualitative Study

Death is a situation of enduring loss which causes various modifications in the family system in terms of relationships, attachment, personal identity and social space. It is a permanent state of deprivation, also involving secondary losses which are a consequence of the principal loss (Parkes, 2001; Shapiro, 2001). The meaning given to the grief and the way it is experienced depends on cultural and individual differences, the relationship with the deceased, the circumstances of the death, and personality and social variables, as well as any concurrent stressors. All these factors will influence the intensity and duration of the grief process (Bowlby, 1980; Gurgel, Kovacs, Mochel, Nakasu, \& Portugal, 2011; Worden, 2003).

The construction of self is based primarily on the interactional patterns and representations that we establish during our life. These factors are decisive in emotional control and socio-emotional regulation (Shapiro, 2001). The death of a loved one or family member may lead to imbalances and losses in terms of self and emotional control and may disturb personal strategies of affection, self regulation and social roles. Thus, there is a need for multiple reorganization and for the bereaved to play an active role in mourning tasks, in order to establish a new balance (Gurgel et al., 2011; Riley, Lamontagne, Hepworth, \& Murphy, 2007; Shapiro, 2001; Worden, 2003). Accordingly, grieving is a process in which the relationship with the world is relearned, and life and the relationship established with the deceased are redefined (Attig, 2004).

Among the many authors who have studied the grief process, Bowlby (1980) was particularly interested in loss in children and adults associated with attachment theory, and his research addressed emotional and affective reactions to loss. He thus developed a model of four 
phases of the grieving process, similar to the work of Parkes (1970), comprising an initial phase of shock and numbness, a phase of yearning and searching for the lost loved one, a phase of disorganization and despair, and lastly a phase of reorganizing behavior.

Theories of grief and loss have changed significantly over time, and most current perspectives consider that it is important to maintain a connection with the deceased, unlike earlier research that argued that the ties which existed in life should be cut (Davies, 2004). As a result, clinical practice has given greater importance to tasks that are used to deal with grief, and to enhance the personal growth of the bereaved through confrontation with loss and selfreflection (Schaefer \& Moss, 2001; Worden, 2003). These tasks can be applied at both the individual and the family level, enabling personal growth as well as sharing of experience by the family, in order to achieve a balanced system and subsequently reinvest in new goals and relationships (Klass, 1999; Worden, 2003).

\section{Parental Bereavement}

The death of a child appears to be contrary to the natural order and is one of the most traumatic events in life. It causes changes at the individual and social level, including the loss of expectations about the future, and loss of identity, roles and parental functions (Alarcão, Carvalho, \& Pelloso, 2008; Barrera et al., 2009; Bittencourt, Quintana, \& Velho, 2011; Davies, 2004; Worden, 2003). There is also evidence of a sense of failure in the parent's role of being responsible for the health and safety of their child, along with feelings of guilt for failing to do something to prevent the child's death (Bittencourt et al., 2011; Worden, 2003).

Although the loss of a child is painful for both parents, there are differences in the way each of them deals with that loss. The mother usually feels more guilt about the loss of the child, due to her inability to prevent the situation that caused the loss, while the father feels a greater 
need to control his emotions, especially associated with the social gender role in Western societies (Barrera et al., 2009; Schwab, 1996; Worden, 2003). The sense of maternal loss is aggravated when the death occurs in an unexpected way, leading to non-acceptance, disorganization and helplessness, and emerging feelings of incomprehension, injustice and resentment that are inherent in the grieving process (Alarcão et al., 2008; Arnold \& Gemma, 2008; Kóvacs, 1992).

The social support network is very important because it allows bereaved parents to express their feelings and forces them to think about the loss and thus elaborate on it, as a means of gratification and strengthening (Arnold \& Gemma, 2008; Oliveira \& Lopes, 2008; Worden, 2003). Frequently the parents' social network and the family itself do not allow themselves to talk about the deceased child (or do not know how to), which may lead the parents to feel that the child is being forgotten, as if he/she never existed (Arnold \& Gemma, 2008). In fact, in the modern Western world (including Portugal, where this study was carried out) there is an expectation that after the funeral, the bereaved person will return to "normal". Consequently, after the first few weeks the social and emotional support from individuals and institutions often dwindles. This can leave parents feeling abandoned and isolated, struggling with their grief more and more silently over time (Barrera et al., 2009). The pain and emotions they experience continue long after this period. Since remembering their children can have a positive impact on their wellbeing, it is very important for them to be able to share those memories. Many parents are able to create a set of strategies, using images and rituals, to ensure that the bond with the child continues present (Arnold \& Gemma, 2008).

\section{From Traditional Grief to Virtual Grief}


Rituals are understood as a set of practices that help to assign a symbolic value to the loss, allowing the bereaved to say goodbye to the deceased and to go through the grieving process (Bousso, Ramos, Frizzo, \& Santos, 2012; Gurgel et al., 2011). In today's cyberspacedominated world, with the increasing influence of social media in our daily lives, we can detect a post-modernist approach to death, involving changes in traditional rituals. Those rituals which were previously personal and traditional in nature now take on a public character (Mueller, 2014; Walter, 1994). More specifically, social networks allow us to express our feelings, and to receive social support from other users, via the posting of images, videos and texts that remind of the deceased and the time before the loss, among others (Arnold \& Gemma, 2008; Attig, 2004; Bousso et al., 2012; Mueller, 2014). Social networks are an easy means of increasing the scope of any information transmitted, regarding death and loss, as well as the speed with which it is transmitted. They allow spatial expansion due to the absence of physical barriers, and also social expansion involving greater interaction between different social groups, regardless of their context (Brubaker, Hayes, \& Dourish, 2013).

These changes in the way we deal with death have both positive and negative aspects. On the one hand, social networks can help develop the grieving process. Writing is seen as a therapeutic process that can help bereaved persons to reorganize their feelings, reducing their sense of helplessness and giving them the idea that they are receiving virtual support from the community. At the same time, they remain in contact with the deceased to some extent, especially when their loved ones' accounts continue active (Bousso et al., 2012; Degroot \& Carmack, 2013; McEwen \& Scheaffer, 2013; Mueller, 2014; Peruzzo, Jung, Soares, \& Scarparo, 2007). However, some authors (Gurgel et al., 2011; Mueller, 2014) argue that the deceased's presence on social networks can cause discomfort to the family due to the possibility of other 
users sharing their information (e.g., sharing secrets that the deceased would not wish to have revealed, thereby "vandalizing" the memory of the deceased). Social network users are able to manage the information they wish to share, but after a user is deceased his/her identity could be modified as a result of shares by other users (McEwen \& Scheaffer, 2013). Some authors also argue that the use of social networks in death can raise moral questions, in the sense that there is no clear understanding of physical death and this could be considered disrespect for the person who has died. Their use may also complicate the grieving process, and may be associated with mental health issues, since it allows many mourners to maintain the notion that the deceased is still alive, in some way (Gurgel et al., 2011). Thus, opinions differ regarding the role of social networks in the grieving process. It is impossible to generalize as to whether their use is positive or negative, since this depends greatly on the idiosyncrasies of each individual (Peruzzo et al., 2007).

\section{Facebook}

Facebook is currently one of the most widely used social networks. Its users are able to establish contact with others and access various types of information. It can also be a means for receiving emotional support, expressing feelings and discussing ideas and topics of interest (Bousso et al., 2012; Brubaker et al., 2013; Chiang \& Huang, 2016; Joinson, 2008; Mendoza, 2014). Activity on Facebook is constant and each user is able to manage his/her own account, taking advantage of the high level of control over privacy. Moods, feelings and opinions can be transmitted through text messages, audio, video, photos, news and comments (Chiang \& Huang, 2016; Mendoza, 2014).

The increased use of Facebook has led to many issues being explored virtually, among them death and loss. People use the social network to express personal feelings and to receive 
social and emotional support, through "likes" and "comments", as a result of the interpersonal relationships that are established. Social support can be provided by one user "liking" some content which has been shared by another, and "comments" are a simple way of expressing compassion, comfort and care for others, through words, thus providing emotional support (Brubaker et al., 2013; Chiang \& Huang, 2016; Mueller, 2014).

Users' behaviors and motivations may differ depending on their beliefs, and certain discomfort and conflicts may also arise. Using Facebook, particularly if the deceased's account remains active, can be a mechanism for maintaining contact with the deceased, as happens in the traditional ritual of visiting graves. The use of social networks is a quicker means of keeping in touch (Mueller, 2014), establishing a connection with the deceased loved one or showing others how important he/she was to them, in order to have their suffering recognized by others. Some may use Facebook to pay tribute, to give thanks and to pass on their condolences to the family, as they would in a traditional way, although others sometimes regard these public statements as attention-seeking behavior (Bousso et al., 2012; Brubaker et al., 2013; Peruzzo, 2007).

On the other hand, sharing about death may give rise to some unexpected encounters with other users, for example, one may become aware of someone's death unexpectedly, or may inadvertently share in the pain of others (Brubaker et al., 2013). In terms of positive aspects, added to the fact that this is a faster way of spreading the news that someone has died, at the same time reaching a greater number of people, it may also be positive for those who are far away and cannot be physically present to pay their last respects (McEwen \& Scheaffer, 2013).

The Facebook accounts of deceased persons can take various forms depending on the wishes of the bereaved. Facebook has specific policies for cases of death, in order to deal with situations of discomfort. An account can effectively be disabled or changed to a memorial page 
(which cannot be manipulated, working as a guestbook and being assigned the status of finitude of life; McEwen \& Scheaffer, 2013). However, some family members may prefer the deceased's account to remain active (Bousso et al., 2012; Brubaker et al., 2013; Mueller, 2014). In these cases, there is often great activity in the first months after the death. There are also those who use the deceased's Facebook account as if he/she were still alive, as long as they have access to his/her password (Brubaker et al., 2013; McEwen \& Scheaffer, 2013).

\section{The Present Study}

Considering the lack of research to date on the role of Facebook in parental grief, this qualitative and exploratory study aims to: a) identify the possible functions of the use of Facebook in maternal grief; b) explore and compare the perceptions about Facebook of mothers more recently bereaved and of those who lost their children longer ago; and c) explore possible relationships between the cause of the child's death and the type of use of Facebook by mothers.

\section{Method}

\section{Participants}

The participants in the study were 11 women, aged between 48 and 66 years $(M=54.72$, $S D=6.01$, who had lost their children between two years and 10 years prior to the study, due to accidents or prolonged illness. Four of these mothers had lost their only child. Six mothers had lost their children over 5 years prior to the study and five of them between 2 and 5 years prior to the study. At the time of the study, two participants were widows, seven were married and two were living with someone (a partner other than the father of the deceased child). Two participants were unemployed, two were retired and the other seven were employed. They had different levels of education (ranging from basic schooling to graduate level).

\section{Procedure}


Participants were required to be at least 18 years of age, to speak Portuguese and to have lost a child between two years and ten years prior to the study. This time interval is specifically related to two aspects: 1) according to many authors (e.g., Bonanno \& Kaltman, 2001), feelings of acceptance of the loss begin to exist around 6/12 months after it occurs, when it becomes possible to take a more active role in facing the pain of loss; and 2) the use of Facebook began to grow in Portugal from 2010. The sample becomes more homogeneous as a result. Mothers of children who had committed suicide were excluded, because there may be feelings of shame and guilt, as well as a constant struggle to forgive the child, leading to a more complicated mourning process (Arnold \& Gemma, 2008; Barbosa, 2014; Worden, 2003). The sample was collected via participation in meetings of grieving parents, direct contact with grieving mothers using a private message on Facebook, and by the "snowball" method.

Prior to the interviews, the objectives of the research were stressed and confidentiality was guaranteed, with the participants giving their informed consent. The interviews lasted between 90 and 120 minutes and were recorded in audio format. A semi-structured interview guide was used, organized into five main thematic blocks: information about the child, the circumstances surrounding the child's death, resources in the grieving process, social support and use of Facebook. Participants also completed a general questionnaire with sociodemographic data (e.g., age, educational background, professional status) and information related to the deceased child (e.g., year of death, age at the time of death, cause of death). After transcription, a qualitative analysis of the participants' responses was undertaken, using the Thematic Analysis method (Braun \& Clarke, 2006). This method allows patterns corresponding to themes to be identified, analyzed and described. After identifying the themes (implicit and explicit ideas throughout the data), an encoding process was conducted, by which the units of meaning were 
organized into specific categories, whenever a particular pattern emerged (Braun \& Clarke, 2006). Triangulation by the researchers helps to ensure the credibility and validity of the research (Miles \& Huberman, 1994). Therefore, raw data responses were individually identified and grouped into themes and subthemes developed by the first author and checked for reliability and validity by the second author until a consensus was reached. The process of data analysis was performed using the software QSR NVivo 10.

\section{Results and Discussion}

Thematic analysis of the interviewees' responses yielded 84 interrelated categories, organized in a hierarchical system. Two main categories were identified - Death and Facebook but only the latter was explored, considering the purpose of this study. This category consists of two sub-categories - functions and perceptions about the use of Facebook. These were analysed in conjunction with the characteristics of the children's deaths and the duration of the grief

process. Some quotations from participants are included within the explanation of each category (names given to respondents are pseudonyms to guarantee anonymity).

\section{Principal Functions of Facebook in Parental Grief}

Six principal functions associated with the use of Facebook were identified by the participants, specifically: receiving support, identifying with other mothers, remembering the child, accessing the child's information, paying tribute to the child, and expressing feelings.

\section{Receiving support.}

Grief is a stage in which the mourner expresses feelings which are important in order for $\mathrm{him} /$ her to restructure and reorganize. However, our society has some difficulty dealing with death, and there are few spaces that allow for sharing, empathy and social support in order to 
minimize the suffering of the bereaved (Barrera et al., 2009; Bittencourt et al., 2011; Bousso et al., 2012; Oliveira \& Lopes, 2008). The results showed that mothers in mourning feel this lack of social support and see Facebook as a place where they will be more accepted, although in the virtual community, and where they can express their feelings.

“We were accepted on Facebook, but are not accepted in society... we are animals! My own family does not accept me, I cannot express my feelings." (Carla, 54 years old, death of child by accident)

Manifestations of grief in cyberspace lead to an increase in the support received, as there is greater tolerance and disinhibition, as well as fewer social constraints. This is also a way of continuing a wake online (Ariés, 2012; Mueller, 2014). Through online sharing, users feel less pressure and stress than when they contact the bereaved in person (Degroot \& Carmack, 2013). The mothers in our study received support on Facebook via "likes" and "comments" posted by other users on the content they shared. Participants also reported receiving support from associations and groups of bereaved parents, both directly and indirectly: through their posts or through contact established with mothers in similar situations who were unconnected to the physical space of the associations. Facebook seems to function as a form of social support (Chiang \& Huang, 2016). This support can be received almost simultaneously from different sources, and the grieving mothers are able to write about their loss and to share their experiences with other mourning mothers. This perceived support enables the necessary restructuring and reorganization of the loss, consequently leading to less intense suffering responses, which is in accordance with Riley et al. (2007). 
"Oh, that is so good, so good. Just one little heart and I know that person read it. At the beginning there were more things than now, but I saw that there were so many people that liked my little boy... It's strange if someone I remember at that moment doesn't say anything." (Clara, 56 years old, death of son by accident)

Although grievers' real-life social networks often find it difficult to provide support, the participants noted that friends of the deceased children and other grieving mothers, as well as the participants' close friends, gave their support both in person and on Facebook. However, extended family tended to withdraw.

"I started using Facebook to seek help, there are groups where other mothers have been through it. For me Facebook is to express feelings without being criticized. Only those who want to give an opinion or put "likes". There are mothers in these groups who understand what we are going through and feel the same as me." (Carla, 54 years old, death of son by accident)

\section{Identifying with other mothers.}

This function is characterized by the perception that mothers in grief are not alone and that other mothers are going through the same process. This identification happens through "likes" that several mothers place on the pages of associations of grieving parents and on the content shared there, and also via the sharing of stories. Support is received and given to other mothers, through conversations by chat or just by putting "likes" and "comments" or sharing posts of mothers who are better able to "put into words" what they are feeling at that moment. 
Research shows that self-help groups are important for many mothers, especially when the social support network is almost non-existent, as these groups allow them to feel better understood, by sharing experiences (Arnold \& Gemma, 2008; Davies, 2004). For the interviewed mothers, Facebook seems to have the same function as real life groups of bereaved parents. They are able to exchange experiences between mothers or simply share feelings or images related to the loss of children. This occurs particularly in grieving parents' groups or through the exchange of private messages, which creates a feeling of mutual support.

"The intention is very good, very good, because we see that there are people with a pain like ours and that we still have the support of these groups to help us; and that there are many people who have no support from anywhere." (Leonor, 53 years old, death of son by accident)

\section{Remembering the child.}

This function is related to the ability to access the account that belonged to the child and see account activity after his/her death, with the shares of friends. This function is also associated with content posted by mothers in their own accounts or the accounts of children so that they are not forgotten, allowing both users and mothers to create positive memories about the deceased, emphasizing how much the child was liked in his/her group of friends (McEwen \& Scheaffer, 2013). In fact, remembering the child reflects one of the positive aspects mentioned by the participants - feeling that others loved the child.

"It's good to see that friends are still posting and I like people to talk about her, because it's a way of feeling that she did not die, that she's still in the thoughts of these people and that 
they still think about her. It makes me feel good because I do not want her to be forgotten by friends or anyone else." (Anabela, 49 years old, death of daughter by accident)

\section{Accessing the child's information.}

Access to public information takes place through visits to the deceased child's timeline where mothers can access and explore information through comments, videos, photos and more. Access to private information occurs if the deceased's password is used to access content that only the deceased could see.

"I spent more than a month reading things. I read all the messages... I read everything, even the private messages. My sister-in-law came here in the few weeks after and my brother-inlaw had his computer and I used it to access my account, but only quick things. As her [dead child's] account was open and I did not know the password, I was afraid to close it and then not be able to open it again." (Anabela, 49 years old, death of daugther by accident)

The results stress the positive role that Facebook can play, enabling mothers in grief to access photos, comments, and other posts that the children have shared in their lifetime, as well as all the content shared by other users after the death that is related to their children. This enables mothers to gain access to content that helps preserve the memory of the child and to feel that they have not been forgotten by their friends (Davies, 2004).

"I see that there are people who continue to write little things, his friends. And I think that all this time has passed, but he is still present in the lives of these people. I feel good about it, I am glad to know that he has not been forgotten, he is still remembered and loved." (Lígia, 57 years old, death of son by accident). 


\section{Paying tribute to the child.}

Tributes are in the form of posts of, for example, music or pictures with phrases dedicated to the deceased or albums created exclusively to pay tribute. Mothers also tend to post about real-life rituals, giving them greater public exposure. Many grieving mothers have a great need to pay tribute to their child. This was mentioned by many participants when discussing the strategies used to cope with the loss.

\section{"I share songs that I know he liked because he really enjoyed singing and dancing. And I share comments about how I feel." (Lígia, 57 years old, death of son by accident)}

These tributes, like the function of remembering the children, allow mothers to feel they are preserving the memory of the children and that they are not forgotten by others. This happens via feedback on their posts, either in their own or in their deceased child's account. By sharing what they feel on Facebook, grieving parents can build stronger and long-lasting memories. Some therapeutic interventions focus on producing materials such as biographies, tributes or memorials so that these parents can feel they are remembering the child, preserving his/her memory and showing the importance that he/she continues to have in their lives (Davies, 2004).

"Each time I make a tribute I always add some photos to her album and I tag her. Recently I was in Jamaica and I tagged her so that the account is always active. Not every day, because it's not necessary." (Anabela, 49 years old, death of daugther by accident)

\section{Expressing feelings.}


This function is related to the way mothers can express what they feel through Facebook posts. Although this is not the most reported subcategory, it seems to cut across the others, since this need was mentioned by the participants as being associated with all of the above functions. Regarding the discussion on strategies to deal with the death, mothers reported that they felt the need to write dedications, dreams and feelings they had; this was something they could do on Facebook. These feelings are often expressed by writing directly to the deceased children, as if they were still present in the physical world (Mueller, 2014).

“On Facebook I can talk, give opinions, make comments... just yesterday I spoke with some people because I was feeling down and I can talk to them, unlike many people that I cannot talk to." (Carla, 54 years old, death of son by accident)

A study by Bousso et al. (2012), on shares by friends of deceased persons, found that this direct communication could be a way for people to feel closer to the deceased. However, the fact that these shares are on Facebook means there is a loss of spontaneity in the way people give condolences to the family. This pattern of posts and expressions of feelings was also observed by the mothers interviewed in this study. Feelings are often initially expressed on the deceased's timeline, which is particularly active immediately after the death. Later, they tend to be transferred to the mother's timeline, with the deceased's timeline only recording activity again on special dates or during festive seasons.

"I also share things on his timeline because it is still active. I share certain things on his timeline on certain occasions. (...) I've been through that stage of looking for tributes to him." (Carla, 54 years old, death of son by accident) 
It is possible to conclude that Facebook plays an important role in the grieving process of some mothers, and it is similar to many real life rituals, which are now beginning to be conducted on and through the virtual world. All these functions are regarded as positive aspects of the use of Facebook, providing greater wellbeing.

\section{Perceptions about the Use of Facebook}

In total, participants reported more positive than negative aspects associated with using Facebook. The number of references to positive aspects is greater, as is the number of participants who discussed this topic.

\section{Negative aspects.}

The interviewed mothers indicated as negative aspects of Facebook specifically the fact that it is "impersonal" or detached, since anyone who has access to the mother's profile can realize almost automatically that she is a mother in mourning, considering the type of shares on her timeline. The situation can also be identified because of "likes" on pages of associations of grieving parents and groups created for people who have gone through this traumatic event.

"I think it is not a support tool because we have to have the notion that Facebook is very impersonal. As soon as we enter a group of grieving parents, we start receiving many things from that group and the 'onlookers' begin to increase in number. I sometimes prefer not to post a lot on Facebook." (Filipa, 58 years old, death of son by illness)

Another negative aspect is related to unpleasant comments which other users may make on mothers' posts, or even incorrect interpretations of some comments by mothers. 
"I see people... some of them that I know go to the association and share, and after that make some comments that if it was me I wouldn't like it! That's why I say I'm not such a big fan of Facebook." (Maria, 66 years old, death of son by illness)

The absence of physical contact and the fact that very little direct dialogue is used to share experiences were also referred to as negative aspects of Facebook, compared to other forms of social support.

"Unfortunately, my Facebook is full of mothers who have lost children, and we occasionally put "likes" on what people post. But there's no conversation, there's no direct contact with the person, there isn't a conversation where each of us shares their experiences." (Margarida, 50 years old, death of son by accident)

Also considered as negative, but with fewer mentions, were an excessive number of shares and exposure of content and images. Several participants stated that at some point they saw images or videos on Facebook about their children that they did not like, and in some cases the number of shares by mothers in mourning was considered excessive and seen as having the potential to perpetuate suffering.

"Sometimes there is excessive sharing about the loss of a child. It won't change anything and they end up suffering even more." (Laura, 63 years old, death of son by accident)

"At the beginning someone shared a video of him racing with his car and I didn't like it. And I told them to delete it." (Leonor, 53 years old, death of son by accident) 


\section{Positive aspects.}

All the positive aspects identified are related to the functions of Facebook described above, specifically the fact that it enhances wellbeing and allows mothers to feel that the children were loved by others and that they will not be forgotten.

"At the beginning I thought about deleting the account, but now I don't want to, because I feel good going there and seeing my son and the things that the friends publish. I'd rather have him there, because there he will always be remembered." (Rosa, 48 years old, death of son by accident)

"I feel good because I can see that they haven't forgotten about him yet. It's a sign that he hasn't left the hearts or the memory of the ones that liked him." (Clara, 56 years old, death of son by accident)

When the characteristics of the participants are analyzed, it seems that the mothers whose children have been deceased for longer (over 5 years) consider Facebook to have more negative than positive aspects (13 vs. 7 references, respectively). On the other hand, more recently bereaved mothers (less than 5 years) reported more positive aspects of Facebook use (16 references vs. 3 references to negative aspects), especially if the children's accounts remain active. For them, accessing information in the deceased's profile, published by the child when he/she was alive and by others after death, can act as a form of consolation. That is why there is more activity in the first months, which is in accordance with other studies (McEwen \& Scheaffer, 2013). Participants whose children died longer ago may not have referred to many 
positive aspects because they have been in the grieving process for over five years, and Facebook only began to be used more intensively in Portugal from 2010 on. However, these respondents reported some positive aspects associated with hi5, another social network widely used before 2010 and very similar to Facebook, with almost the same functions. On the other hand, because our sample was limited to 11 participants, these differences about the positive and negative aspects according to the length of grief should be better explored using bigger samples.

According to a study by Miles (1984) on the emotional, behavioral and cognitive symptoms associated with the pain of loss, parents in mourning undergo a three-step process, starting with a period of numbness and shock associated with the first moments of loss. This is followed by a period of intense pain, associated with the normal grieving process in terms of physical symptoms, and behavioral and cognitive changes, as well as the presence of feelings of guilt, anger and frustration. It is at this stage that there is a need to keep in contact with the deceased (e.g., through his/her belongings, photos, etc.) and a need to give meaning to the loss, which can also happen by providing support to other parents who have gone through a similar situation. Finally, during the reorganization period a decrease in changes associated with the loss is noted and there is an identity reorganization. The positive and negative aspects that mothers attributed to Facebook can be understood in the light of Miles's theory (1984). Facebook may be perceived as more positive by mothers who are in the severe pain period, who feel the need to visit the deceased's profile more often and to absorb a set of memories that can be important for grieving tasks and therapeutic interventions. Mothers who have been grieving for longer may be in the reorganization period, beginning to reorganize their identity. In addition, it was found that over time the number of shares and emotional reactions tend to decrease, which coincides with the results of other studies (Bousso et al., 2012). 
Another interesting finding of this study is that, besides the participants who had been mourning for longer, those whose children had died due to prolonged illness (and not suddenly by accident) also mentioned more negative aspects. It is a known fact that the cause of a death influences how grief is experienced (Arnold \& Gemma, 2008; Worden, 2003). In the case of sudden death grief is even more difficult, since there is the feeling that people in mourning are not living the reality and especially the feeling that there was no chance to say goodbye and many things were left unsaid (Worden, 2003).

"The worst disappointment that I had at the time, after all, was not letting me see him. We had to come home and I lay down on his bed and started screaming. (...) It was the crying, the emptiness; 'I have lost everything, I have nothing!' I would look at my husband, but it wasn't enough..." (Clara, 56 years old, death of son by accident)

In the case of prolonged illness, where there are early warnings of death, there is a better adjustment to grieving, because parents have more time to prepare themselves and the chance to talk to the patient about death and some decisions that should be taken, where the patient can have active participation (Schaefer \& Moos, 2001).

"We had time to arrange everything, even what he wanted to do with his belongings and who things would be for and what I should do with them." (Susana, 48 years old, death of son by illness)

"When they told me that he was dead I said it was a lie, I threw myself to the ground and screamed so much... I just wanted to break everything! I just had time to get dressed and I 
started running down the street. When I got to the avenue, my God..." (Margarida, 53 years old, death of son by accident)

We can therefore state that at an early stage Facebook can be perceived as a positive tool for dealing with loss, due to its functions, and especially by mothers who have lost children unexpectedly. Over time it is normal that the number of shares will decrease, and Facebook may be regarded as less essential than it was in the early days.

\section{Conclusion}

There have been significant changes in how we experience and deal with the death and loss of loved ones, specifically changes in rituals that occur over time, and the way we pay tribute and honour the memory of those who have departed. These changes are heavily linked to our unfettered use of the virtual world to keep up to date with new experiences, realities and knowledge, such as via the use of Facebook (Gulgel et al., 2011; Mueller, 2014; Pantti \& Sumiala, 2009). Actually, Facebook seems to fill many of the gaps that exist outside the virtual world in the grieving process of mothers, such as a lack of support, since there is greater openness in cyberspace. Consequently, this social network is seen as a way for mothers to receive social support, which is possible due to fewer constraints regarding the expression of feelings. This social support may arise from several sources, almost simultaneously, and aids restructuring and reorganizing within the grieving process (Riley et al., 2007).

This study also draws attention to possible differences in the perception that mothers have regarding the use of Facebook depending on which stage of the grieving process they are in. The mothers interviewed revealed that in the early stages there is a greater need to use this social network to express feelings and to access information about their children, whether public or 
private, and they see it as a positive feature in the grieving process, implying more active participation by the mourner (Worden, 2003). On the other hand, in more advanced stages of mourning, that is, when the child's death occurred more than five years earlier, the mothers consider that Facebook is no longer such an important resource, and may even be regarded as something negative. However, it is necessary to consider the type of death, as unexpected deaths do not allow for preparation for the end of life or an opportunity for mothers to say goodbye to their children, whereas deaths from prolonged illness, where there is advance notice that death is coming soon, allow for better adjustment in grief. These aspects also influence the type and the number of Facebook shares by these mothers, as in the case of unexpected deaths there is a feeling that something was left unsaid and Facebook is seen as an important resource for the externalization of feelings by mothers (Schaefer \& Moos, 2001). However, over time it appears that the number of shares tends to decrease, although there is more activity in the deceased's account (if it continues active) and in profiles of mothers in mourning on special occasions and during festive seasons (Bousso et al., 2012).

There are, however, some limitations to this research. Despite having attained theoretical saturation, the sample was not balanced in the sense that there were more participants who had lost their children due to sudden death $(n=8)$ than prolonged illness $(n=3)$. Heterogeneity in the family make-up of each participant was also evident, which may influence how participants perceived support received outside the virtual world, thus influencing the use of Facebook to a greater or lesser degree. Despite these limitations, the results provide an important contribution to this area, given that there is a lack of studies on the use of social networks in the grieving process of mothers, and the urgent need to understand why grief is being increasingly experienced on social networks, particularly on Facebook. 
In future research it would be useful to study the impacts that the media in cyberspace have on the maternal grief process. In the case of unexpected deaths (e.g., accidents) there is a lot of news that could further increase the suffering of these mothers due to inappropriate comments by internet users, or even news that distorts the facts. It would also be important to investigate how social networks can play a key role in therapeutic intervention, with new methods of intervention for these specific situations of bereaved mothers.

As a final note, it would be useful if Facebook had a definition that would allow all posts made in life (and also those made after death by others) to be grouped into some format. If the immediate family wanted to cancel the accounts of their loved ones, this would allow them to keep a document which they could use whenever they felt the need. This would mean that the memories would not be lost but the deceased would not continue living virtually.

\section{References}

Alarcão, A., Carvalho, M., \& Pelloso, S. (2008). The death of a young son in violent circumstance: Understanding the experience of the mother. Revista Latino-Americana de Enfermagem, 16(3), 341-347.

Ariés, P. (2012). História da morte no Ocidente [History of death in Occident]. Rio de Janeiro: Nova Fronteira.

Arnold, J., \& Gemma, P. (2008). The continuing process of parental grief. Death Studies, 32, 658-673. doi:10.1080/07481180802215718

Attig, T. (2004). Meanings of death seen through the lens of grieving. Death Studies, 28, 341360. doi:10.1080/07481180490432333 
Barrera, M., O’Connor, K., D’Agostino, N. M., Spencer, L., Nicholas, D., Jovcevska, V., ... Schneiderman, G. (2009). Early parental adjustment and bereavement after childhood cancer death. Death Studies, 33, 497-520. doi:10.1080/07481180902961153

Bittencourt, A., Quintana, A., \& Velho, M. (2011). A perda do filho: Luto e doação de órgãos [The loss of the child: Grief and organ donation]. Estudos de Psicologia, 28(4), 435-442.

Bonanno, G., \& Kaltman, S. (2001). The varieties of grief experience. Clinical Psychology Review, 21, 705-734. doi:10.1016/S0272-7358(00)00062-3

Bousso, R., Ramos, D., Frizzo, H., \& Santos, M. (2012). A prática do luto interativo no Facebook [The practice of interactive mourning on Facebook]. Simsocial. Symposium on digital technologies and sociability. Retrieved on 14 june, 2016 from http://docplayer.com.br/3818221-A-pratica-do-luto-interativo-no-facebook.html

Bowlby, J. (1980). Attachment and loss (Vol. 3 Loss: Sadness and depression). New York: Basic Books.

Braun, V., \& Clarke, V. (2006). Using thematic analysis in psychology. Qualitative Research in Psychology, 3, 77-101. doi:10.1191/1478088706qp063oa

Brubaker, J. R., Hayes, G. R., \& Dourish, P. (2013). Beyond the grave: Facebook as a site for the expansion of death and mourning. The Information Society, 29, 152-163. doi:10.1080/01972243.2013.777300

Chiang, P., \& Huang, Y. (2016). How to create social support on Facebook. International Journal of Electronic Commerce Studies, 7, 1-20. doi:10.7903/ijecs.1243

Davies, R. (2004). New understandings of parental grief: Literature review. Journal of Advanced Nursing 46, 506-513. doi:10.1111/j.1365-2648.2004.03024.x 
DeGroot J.M., \& Carmack, H.J. (2013). “It may not be pretty, but it’s honest”: Examining parental grief on the Callapitter blog. Death Studies, 37, 448-470. doi:10.1080/07481187.2011.649940

Gurgel, W., Kovács, M., Mochel, E., Nakasu, C., \& Portugal, P. (2011). Luto virtual: O processo de elaboração do luto no ciberespaço [Virtual grief: The process of mourning in cyberspace]. Cadernos de Pesquisa, 18(1), 7-16.

Joinson, A. N. (2008). Looking at, looking up or keeping up with people? Motives and use of Facebook. In Proceedings of the SIGCHI conference on Human Factors in Computing Systems (pp. 1027-1036).

Klass, D. (1999). The spiritual lives of bereaved parents. Philadelphia: Brunner/Mazel.

Kovácks, M. J. (1992). Morte e desenvolvimento humano [Death and human development]. São Paulo: Casa do Psicólogo.

McEwen, R., \& Scheaffer, K. (2013). Virtual mourning and construction on facebook: Here are the terms of use. Bulletin of Science, Technology \& Society, 33, 64-75. doi: $10.1177 / 0270467613516753$

Mendoza, R. I. (2014). Representaciones de Facebook: Nomenclaturas de vida ante la ley, la amistad y la muerte [Representations of Facebook: Nomenclatures of life in front of law, friendship and death]. Cultura y representaciones sociales, 8(16), 137-174.

Miles, M. S. (1984). Helping adults mourn the death of a child. In H. Wass \& C. A. Corr (Eds.), Childhood and death (pp. 219-241). Washington, DC: Hemisphere Publishing Corp.

Miles, M. B., \& Huberman, A. M. (1994). Qualitative data analysis: An expanded sourcebook (2nd ed.). Thousand Oaks: SAGE Publications. 
Mueller, L. (2014). Memorial facebook. Meu epitáfio e minha página. As representações da morte no ciberespaço [Memorial facebook. My epitaph and my page. The representations of death in cyberspace]. Revista Uninter de Comunicação, 2(2), 126-143.

Oliveira, J., \& Lopes, R. (2008). O processo de luto no idoso pela morte de cônjuge e filho [The process of mourning in the elderly for the death of spouse and child]. Psicologia em Estudo, 13(2), 217-221.

Pantti, M., \& Sumiala, J. (2009). Till death do us join: Media, mourning rituals and the sacred centre of the society. Media, Culture \& Society, 31, 119-135. doi:10.1177/0163443708098251

Parkes, C.M. (2001). Bereavement: Studies of grief in adult life (3rd ed.). London: Routledge.

Parkes C.M. (1970). Seeking and finding a lost object. Evidence from recent studies of the reaction to bereavement. Social Science and Medicine, 4, 187-201.

Peruzzo, A. S., Jung, B. M. G., Soares, T., \& Scarparo, H. B. K. (2007). A expressão e a elaboração do luto por adolescentes e adultos jovens através da internet [The expression and elaboration of mourning for adolescents and young adults through the internet]. Estudos e Pesquisas em Psicologia, 7(3), 449-461.

Riley, L., Lamontagne, L., Hepworth, J., \& Murphy, B. (2007). Parental grief responses and personal growth following the death of a child. Death Studies, 31, 277-299. doi:10.1080/07481180601152591

Shapiro, E. (2001). Grief interpersonal perspective: Theories and their implications. In Stroebe, Hansson, \& Stroebe (Eds.), Handbook of bereavement research: Coping, consequences and care (pp. 301-327). Washington, DC: American Psychological Association. 
Schaefer, J. A., \& Moos, R. A. (2001). Bereavement experiences and personal growth. In M. Stroebe, R. Hansson, W. Stroebe \& H. Schut (Eds.), Handbook of bereavement research: Consequences, coping, and care (pp. 145-167). Washington, DC: American Psychological Association.

Schwab, R. (1996). Gender differences in parental grief. Death Studies, 20, 103-113. doi:10.1080/07481189608252744

Walter, T. (1994). The revival of death. London: Routledge.

Worden J.W. (2003). Grief counselling and grief therapy: A handbook for the mental health practitioner. East Sussex: Brunner-Routledge. 